\title{
Role of Restrictive Endoscopic Procedures in Obesity Treatment
}

\author{
Hang Lak Lee \\ Department of Internal Medicine, Hanyang University Hospital, Seoul, Korea
}

It is well recognized that obesity is a big problem and it can induce large economic burden. Obesity affects about $40 \%$ people in the America alone and obesity also is the worldwide problem, with about 400 million obese adults. Moreover, another problem of obesity is the increasing prevalence of overweight children. Though bariatric surgery remains the gold treatment modality in the obesity treatment, endoluminal approaches may have the meaningful role for weight control. Endoscopists should have a role in the management of obesity because endoluminal therapies demonstrate their safety and efficacy over the coming years. Endoluminal therapies can be summarized by above methods: space occupying, malabsorption method, and reduction of gastric volume. In this review, we will introduce various restrictive endoscopic procedures in obesity treatment. Clin Endosc 2017;50:17-20

Key Words: Endoscopy; Obesity; Balloon

\section{INTRODUCTION}

In spite of the low complication rates related to laparoscopic bariatrics, there is an increasing attention in endoluminal and/or transgastric instruments for weight loss procedures.

Interest in endoluminal treatments for the obese has been present for many years. The first breakthrough in endoluminal therapy has been the intragastric balloon (IGB), currently the Orbera balloon, but previously referred to as the Bioenterics intragastric balloon (BIB). The IGB provides a short term supplemental therapy. Nowadays, several companies are developing various balloon devices for obesity treatment. This summary will highlight the various developments on IGB.

Received: January 18, 2017 Accepted: January 20, 2017

Correspondence: Hang Lak Lee

Department of Internal Medicine, Hanyang University Hospital, 222-1 Wangsimni-ro, Seongdong-gu, Seoul 04763, Korea

Tel: +82-2-2290-8354, Fax: +82-2-2298-9183, E-mail: alwayshang@hanyang.ac.kr

cc This is an Open Access article distributed under the terms of the Creative Commons Attribution Non-Commercial License (http://creativecommons.org/ licenses/by-nc/3.0) which permits unrestricted non-commercial use, distribution, and reproduction in any medium, provided the original work is properly cited.

\section{RESTRICTIVE ENDOSCOPIC PROCEDURES}

\section{Intragastric ballooning}

Various space-occupying devices are used in the world. Nowadays, they are intended to act as a bridging therapy to bariatric surgery by decreasing the patients' body mass index (BMI) with the using of a balloon in the gastric space. ${ }^{1-6}$ The first clinically reliable balloon received contrast enhancement (CE) mark in 1998 and has become the world leader in intraluminal weight loss devices. The Orbera balloon also known as the BIB has been placed in over 250,000 patients. This balloon was approved by the Food and Drug Administration (FDA) for US use in 2015.

The balloon is inserted into the stomach through the oral cavity and esophagus using an endoscopic procedure. During procedure, the patient is under sedation. After balloon insertion, balloon is filled with methylene blue mixed saline water, therefore, it expands into a spherical shape balloon. The balloon can be filled with various amounts of saline (from 400 to $700 \mathrm{cc}$ ) to best match the patient's gastric structure. The intra-gastric balloon should be removed approximately after 6 months.

The $\mathrm{BIB}^{\mathrm{ix}}$ System is currently being tested (Allergan, Irvine, CA, USA). 


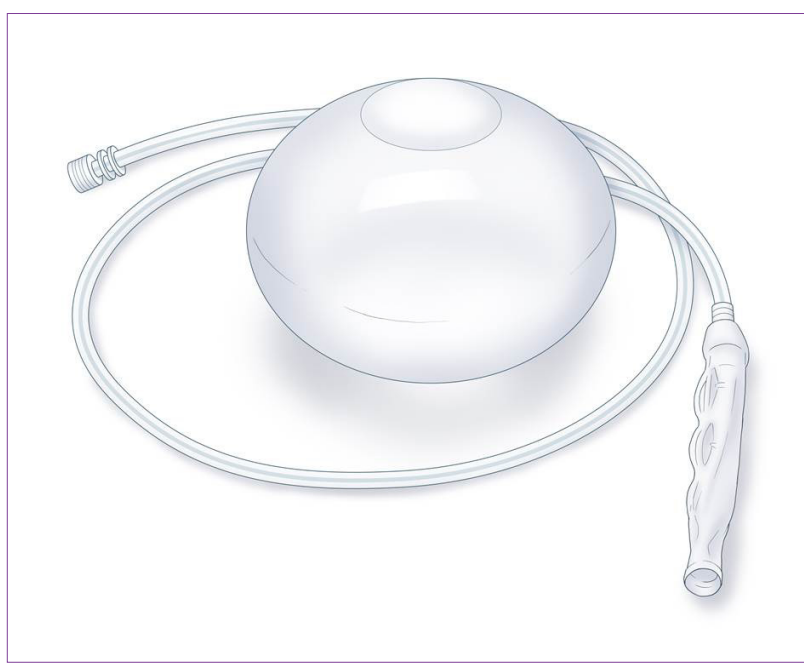

Fig. 1. This is Bioenterics intragastric balloon (BIB) System. It is saline filled space-occupying balloon endoscopically placed into the stomach.

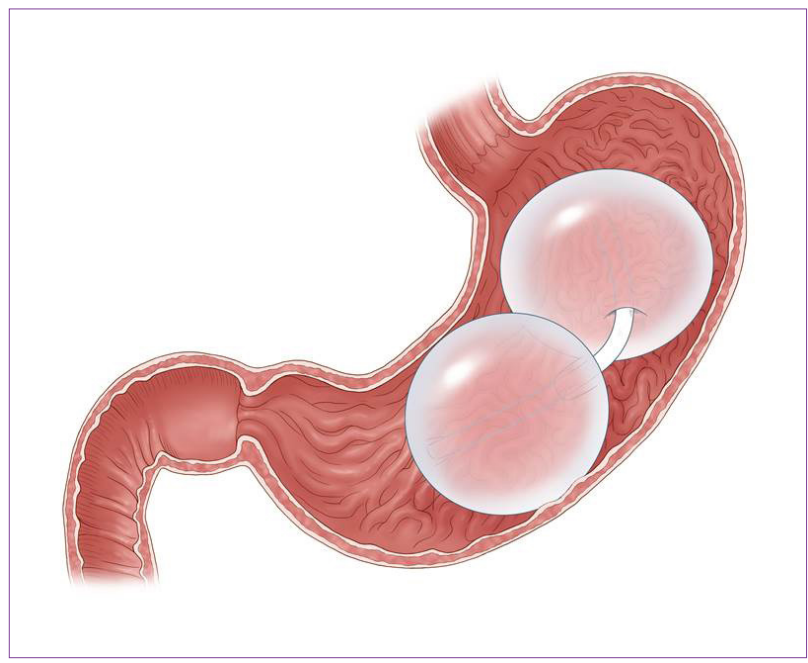

Fig. 2. This system is a gastric balloon with multiple compartments. This system has failure detection systems to enable early detection.

Fig. 1 shows this System. This System is a saline-filled balloon that is placed into the gastric space with using gastroscopy. There was large scaled data about the BIB System. Total about 2,500 patients were enrolled with a mean BMI of 44.4. This system was introduced to these patients. Improvement of BMI and obesity related diseases were evaluated. After 6 months, mean BMI and excess body weight loss (EWL) were $35.4 \pm 11.8$ and 33.9 $\pm 18.9^{7} .^{7}$ Obesity-related parameters such as fasting low density lipoprotein cholesterol, blood glucose, triglyceride, and blood pressure was significantly improved. HbAlc level was significantly decreased in $87.2 \%$ among 488 diabetes patients. There were two mortality cases associated with balloon placement and these patients had a history of gastric surgery. The rate of complication was about $2.8 \%$. BIB System within a multidisciplinary weight management pro-

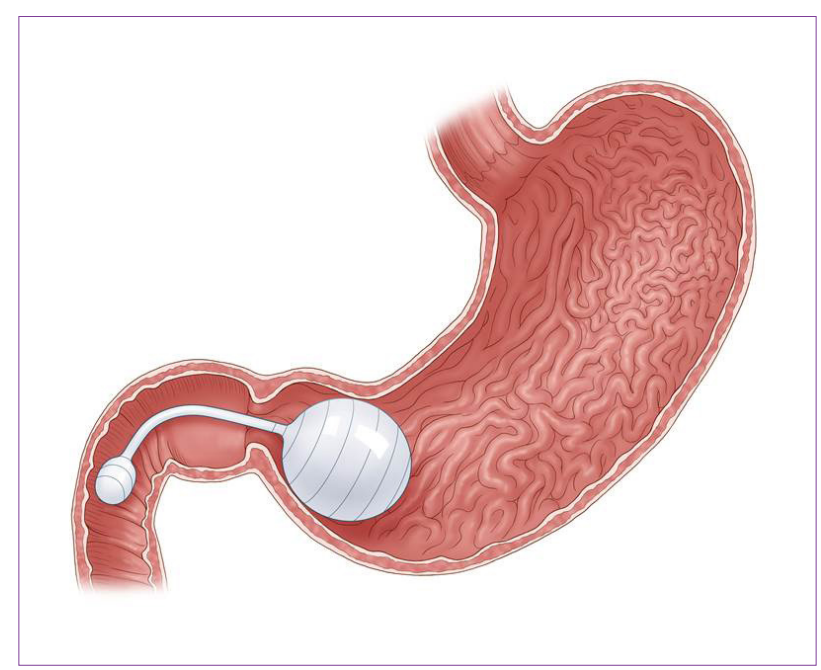

Fig. 3. This system is TransPyloric Shuttle (TPS). This system restricts food ingestion with repeatedly blocking of the pylorus.

gram is a relatively short term effective procedure for weight control, but it is not possible to certify its potential to maintain the weight for a long time.

Fulfillium (Napa, CA, USA) is developing a balloon having multiple compartments. This system has failure detection systems to enable early detection, therefore, endoscopist can remove a leaking balloon prior to collapse, and avoid passage of it to the duodenum (Fig. 2). Based on previous experience with balloon technology, this method is appropriate; however, it is the safety profile that contributes to its limited use.

Other available balloons are the Reshape Balloon, which can provide similar weight loss as the Orbera. Unlike the Orbera, these balloons are in a fixed position within the stomach and as a result there is $26 \%$ incidence of significant ulceration along with a $2 \%$ incidence of spontaneous balloon deflation. ReShape Medical (San Clemente, CA, USA) performs to a prospective, non-randomized, multicenter study designed to implant up to $20 \mathrm{CE}$-marked ReShape ${ }^{\text {mit }}$ Balloons in twenty patients with BMI between 30 and $40 .{ }^{8}$ Enrolled patients will be followed after videotaped endoscopic placement of the 900 cc dual balloon design at 180 days and again 210 days for an additional endoscopy documenting post-removal mucosa.

From the clinical view, the IGB can cause three dominant intolerance symptoms: nausea (vomiting), reflux and abdominal pain, all of which are prophylactically treated before and after balloon placement to avoid "early removal". At present, intolerance symptoms which can lead to early removal occur in $26 \%$ of patients. Using only the large Orbera data, the incidence of ulceration, deflation with migration, and small bowel obstruction are negligible. 


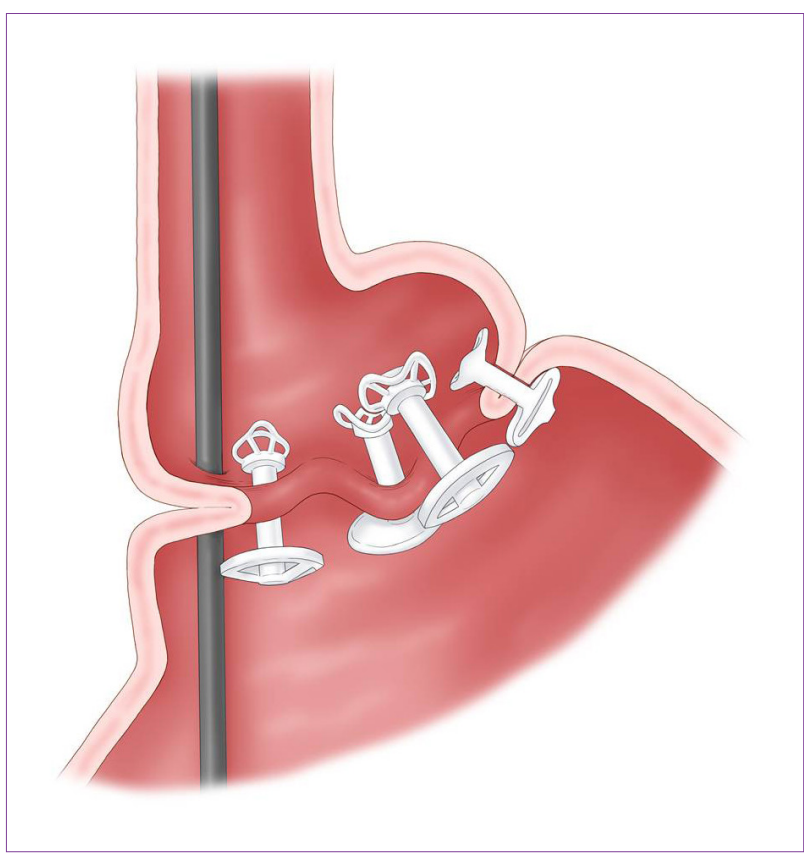

Fig. 4. BaroSense Trans-Oral Endoscopic Restrictive Implant System ${ }^{\mathrm{TM}}$ (TERIS).

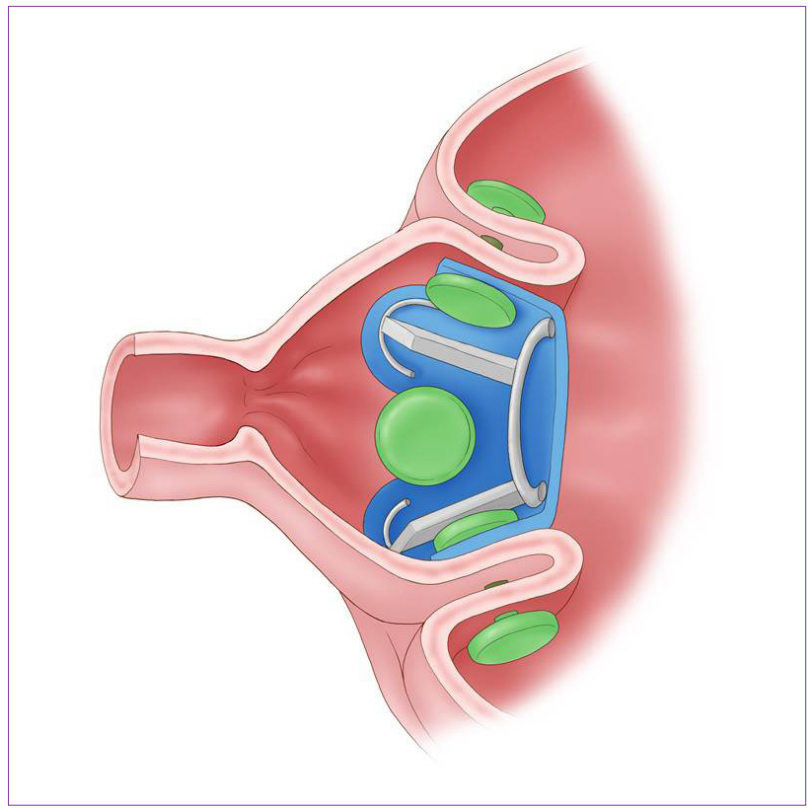

Fig. 5. EndoSphere SatiSphere ${ }^{\mathrm{TM}}$, an endoscopically placed device to increase the contact time of food as it traverses the duodenum.

\section{Other restrictive methods for obesity treatment}

BAROnova Therapeutics (Goleta, CA, USA) is making the TransPyloric Shuttle ${ }^{\text {tw }}$ (TPS) (Fig. 3). This system restricts food ingestion with repeatedly blocking of the pylorus. And therefore, it makes food to increase the contact time within stomach. ${ }^{9}$ TPS can be performed with endoscopy under sedation. It does not need any fixation to anchor this device. Pilot studies have proven safety and initial efficacy of the product with significant EWL at three months.

BaroSense (Redwood City, CA, USA) has developed the Trans-oral Endoscopic Restrictive Implant System ${ }^{\text {mix }}$ (TERIS) (Fig. 4). This system is located in stomach cardia area, therefore, this system can induce early and prolonged satiety. ${ }^{10}$ This system is currently enrolling patients in a phase 1 trial with a secondary objective to perform a preliminary evaluation of the efficacy to guide their pivotal trial.

EndoSphere (Redwood City, CA, USA) has developed SatiSphere ${ }^{\text {mix }}$, an endoscopically placed device increasing the food contact time (Fig. 5). Its length is about $20-25 \mathrm{~cm}$, this system is self-anchored in the distal stomach or proximal duodenum, and, it makes increased hormonal signaling, thereby causing early satiety and downregulation of glucose production. Ultimately, this system would be removed between 6 and 18 months and act as an adjunct to diet and exercise. A small study of 11 patients was performed and showed 12\% EWL at 1 month without any adverse events.

\section{CONCLUSION}

Endoscopic endoluminal treatment of obesity can be a noninvasive, cost-effective, and relatively safer option than bariatric surgery. However, there are many debates according to the long efficacy, economic feasibility and durability of these procedures. Anyway, role of therapeutic endoscopist is very important in the obesity management in aspects of the primary modality for managing complications that occur after bariatric surgery as well as endoscopic endoluminal treatment of obesity. In the near future, role of gastroenterologists will be more important in the management of obesity and its related problems.

\section{Conflicts of Interest}

The author has no financial conflicts of interest.

\section{REFERENCES}

1. Ramhamadany EM, Fowler J, Baird IM. Effect of the gastric balloon versus sham procedure on weight loss in obese subjects. Gut 1989;30:1054-1057.

2. Hogan RB, Johnston JH, Long BW, et al. A double-blind, randomized, sham-controlled trial of the gastric bubble for obesity. Gastrointest Endosc 1989;35:381-385.

3. Meshkinpour H, Hsu D, Farivar S. Effect of gastric bubble as a weight reduction device: a controlled, crossover study. Gastroenterology 1988;95:589-592.

4. Benjamin SB, Maher KA, Cattau EL Jr, et al. Double-blind controlled trial of the Garren-Edwards gastric bubble: an adjunctive treatment for exogenous obesity. Gastroenterology 1988;95:581-588.

5. McFarland RJ, Grundy A, Gazet JC, Pilkington TR. The intragastric 


\section{C cumical enooscopy}

balloon: a novel idea proved ineffective. Br J Surg 1987;74:137-139.

6. Nieben OG, Harboe H. Intragastric balloon as an artificial bezoar for treatment of obesity. Lancet 1982;1:198-199.

7. Genco A, Bruni T, Doldi SB, et al. BioEnterics intragastric balloon: the Italian experience with 2,515 patients. Obes Surg 2005;15:1161-1164.

8. ReShape Medical Inc. Reshape intragastric balloon for the treatment of obesity (Italy III) [Internet]. Bethesda: ClinicalTrials.gov; c2009 [updated 2015 Sep 10; cited 2010 Apr 11]. Available from: https://clinicaltrials.gov/
ct2/show/NCT01024465

9. Talarico JA, Brethauer SA, Schauer PR. Primary endoluminal techniques for weight loss. In: Thompson CC, Ryan MB, eds. Bariatric endoscopy. New York: Springer; 2013. p. 195-204.

10. Biertho L, Hould FS, Lebel S, Biron S. Transoral endoscopic restrictive implant system: a new endoscopic technique for the treatment of obesity. Surg Obes Relat Dis 2010;6:203-205. 